\title{
Rotavirus vaccines at the threshold
}

\author{
The latest trials of a live, oral quadrivalent rhesus rotavirus vaccine may open the door \\ to prevention of rotaviral diarrhea.
}

IN 1998, on the 25th anniversary of the discovery of rotavirus, the medical community is likely to be delivered an extraordinary gift in the form of the first vaccine that is proven to protect against rotavirus diarrhea, a severe childhood disease. The product is a live, oral, quadrivalent rhesus rotavirus vaccine, developed by Kapikian and colleagues ${ }^{1}$. It will be administered in three doses at the time of a child's routine immunizations (two to six months). Two papers, published in the New England Journal of Medicine ${ }^{2}$ and the Lancet $^{3}$, report the very positive results of what has been a long and tortuous path to a rotavirus vaccine.

When rotavirus was discovered by Bishop and colleagues ${ }^{4}$ in Australia, diarrhea was recognized to be a common childhood illness and, in the developing world, it ranked as the most or second most common cause of death among those under five years of age (see figure). But an etiologic agent-such as Salmonella, Shigella or Vibrio cholerae, could be found in fewer than $10 \%$ of hospitalized cases. Within five years of its discovery, rotavirus was implicated in $20-60 \%$ of hospitalized cases of diarrhea. It was estimated ${ }^{5}$ that, of the 3 million diarrheal deaths per year, more than 800,000 could be attributed to rotavirus (see figure). Because rotavirus
ROGER I. GLASS ${ }^{1}$, JOSEPH S.

\section{BRESEE ${ }^{1}$, UMESH PARASHAR ${ }^{1}$, MARK}

MILLER $^{2} \&$ JON R. GENTSCH ${ }^{1}$

affected rich and poor children alike, in both developed and developing countries, it seemed unlikely that traditional public-health measures aimed at improving water, food or sanitation would alter the incidence of the disease. Attempts at prevention needed to be directed toward the development of safe and effective vaccines.

The vaccine now tested was developed ${ }^{1}$ from a rotavirus strain (serotype 3 ) originally isolated from a rhesus monkey with diarrhea. To broaden protection against the three other rotavirus serotypes commonly found in humans (types 1, 2 and 4), reassortant strains were prepared and combined in a quadrivalent vaccine. The rotavirus genome has 11 segments, and each reassortant was composed of a single gene segment encoding the main outer capsid protein (VP7) responsible for viral neutralization of each of the three serotypes, with the remaining ten segments coming from the parent rhesus strain.

Many epidemiological studies have shown that, in children, natural immu- nity develops after the first (and then subsequent) infection. Moreover, with each infection a child's risk of severe disease is diminished ${ }^{6,7}$. The vaccine acts by a similar mechanism and, when administered early, ensures that the child's first infection does not lead to illness.

Perez-Schael et al. ${ }^{2}$ describe a catchment trial in Venezuela, involving over 2,200 children from a poor urban area of Caracas. Efficacy of the vaccine ranged from $48 \%$ against all episodes of rotavirus diarrhea, to $70 \%$ against hospitalization and $75 \%$ against dehydrating disease. Joensuu and colleagues ${ }^{3}$ studied children in Finland, where $16 \%$ of 1,207 placebo recipients developed rotavirus diarrhea, $8 \%$ had severe illness and 1.3\% were hospitalized. But the vaccine had an efficacy of $66 \%, 91 \%$ and $100 \%$ against these three outcomes, respectively. These studies extend our understanding of the behavior of the vaccine in different settings, and lay out some of the challenges ahead for implementing programs based on the use of this-and future-vaccines (see table).

In the United States, as in other industrialized countries, rotavirus is generally mild and rarely fatal ( $20-40$ deaths per year), although it incurs substantial morbidity and costs $^{8}$. Around 50,000 children are hospitalized per year, representing $3-4 \%$ of all

\author{
IMAGE \\ UNAVAILABLE \\ FOR \\ COPYRIGHT \\ REASONS
}

Estimated global distribution of the 800,000 annual deaths due to rotavirus diarrhea. Rotavirus is the most common cause of acute childhood gastroenteritis. Although it mainly affects children in developing countries, it also causes morbidity in the developed world. PerezSchael et al. ${ }^{2}$ and Joensuu et $a .^{3}$ have tested a live, oral quadrivalent rhesus rotavirus vaccine in Venezuela and Finland, respectively, and the results indicate that the virus could protect against this severe diarrheal disease. 
Summary of tetravalent human-rhesus reassortant vaccine efficacy studies

\begin{tabular}{lcccccc}
\hline Country & \multicolumn{1}{c}{$\begin{array}{c}\text { Age } \\
\text { groups }\end{array}$} & $\begin{array}{c}\text { No. enrolled, } \\
\text { vaccinated/ } \\
\text { placebo }\end{array}$ & $\begin{array}{c}\text { All rotavirus diarrhea } \\
\text { Efficacy } \\
\text { Incidence* } \\
\text { (V/P) }\end{array}$ & $\begin{array}{c}\text { Severe rotavirus diarrhea } \\
\text { Efficacy }\end{array}$ & $\begin{array}{c}\text { Incidence } \\
\text { IV/P) }\end{array}$ \\
USA $^{10}$ & 5-25 weeks & $403 / 400$ & 49 & $13 / 25$ & 80 & $2 / 9$ \\
USA $^{11}$ & $2-6$ months & $347 / 348$ & 50 & $11 / 23$ & 64 & $2 / 8$ \\
Finland $^{3}$ & 3-5 months & $1190 / 1208$ & 68 & $1 / 9$ & 91 & $0.2 / 4$ \\
Venezuela $^{2}$ & 8-18 weeks & $1112 / 1095$ & 48 & $3 / 6$ & 88 & $0.15 / 1$ \\
\hline
\end{tabular}

Included are studies using the vaccine dose and administration schedule to be recommended for use; that is, three doses of $4 \times 10^{5}$ plaque-forming units.

*Episodes $/ 100$ child years in recipients of vaccine $(V)$ or placebo (P).

hospitalizations in children under five years of age. The economic impact exceeds $\$ 300$ million in medical costs and $\$ 1$ billion in total costs, including indirect costs such as the loss of salary of the care-giver?. Two multi-center trials of the rotavirus vaccine had been conducted previously in the United States and, although both had shown $50 \%$ efficacy against all rotavirus diarrhea and $80-90 \%$ efficacy against severe disease, they did not have enough hospitalizations to predict efficacy against this most costly outcome. But the studies of Perez-Schael et al. ${ }^{2}$ and Joensuu et al. ${ }^{3}$ now provide confirmation that the vaccine will be particularly effective against hospitalization. Moreover, it protected against nosocomial rotavirus infections as well.

Perez-Schael et al. are the first to show the potential usefulness of this rotavirus vaccine in a developing country. Two previous trials in Brazil and Peru, using a 10fold lower dose of the same vaccine, gave only partial protection. Furthermore, earlier candidate rotavirus vaccines that looked promising when tested in developed countries, showed little efficacy when tested in developing countries. These failures could have been due to vaccine potency, viral interference in the gut, or the design and execution of the trials. But Perez-Schael and colleagues obtained results comparable to those in Finland and the United States, indicating that live, oral vaccines clearly have a use in the developing countries where they are most needed. For some of these countries, such as Venezuela, this success has led them to consider taking the next obvious step-to begin a demonstration project and determine the effectiveness of the vaccine when it is incorporated into the Expanded Programme on Immunization.

Large-scale use of the vaccine should provide information about the risk of un- common side-effects, the efficacy of two doses of vaccine versus three, the costeffectiveness of the program and, ultimately, whether rotavirus-associated hospitalizations and deaths can be prevented on a large scale. Globally, however, more research is needed before rotavirus vaccines can be added to the routine schedule of childhood immunizations. The first vaccine heading for licensure has never been tested in African or Asian children, and past experience with the low immunogenicity of oral polio vaccines in India would caution against rash introductions before further field testing.

Unlike children in developed countries, children in tropical developing countries experience most of their severe rotavirus diarrhea in the first year of life, so vaccines will have to be delivered early on-perhaps at birth. Testing a birth dose and establishing its efficacy in field trials will take three to four years. Moreover, extensive epidemiology to examine the disease burden or rotavirus diarrhea and assess the cost-effectiveness of an immunization program will be critical in many countries, to establish the local need for the vaccine and to determine how best to monitor the outcome of an immunization campaign. And even if countries wanted to begin using the vaccine tomorrow, supply is not available and initial (although not subsequent) costs are likely to be beyond the range of other childhood vaccines sold to developing countries. Nonetheless, the first vaccine is prepared from virus grown in tissue culture, so once the development costs have been covered, and once competition or local production begins, the price of the vaccine could be quite low.

The 25th-anniversary gift of a first generation of licensed rotavirus vaccines may soon be with us and, given the incomplete protection of this vaccine against mild disease, the modest rate of adverse side-effects, and the initial cost, the door is open to the next generation of vaccines. Other candidate vaccines that are being considered include other rotavirus strains of human and animal origin, virus-like particles and inactivated strains, and microencapsulated products. But the basics of pathogenesis, such as the mechanisms of immunity, virulence and host range remain unclear, and it is amazing to see how far the empirical approach to vaccine development has come without a more complete understanding of the scientific basis of disease and immunity.

1. Kapikian, A.Z., Hoshino, Y., Chanock, R.M. \& PerezSchael, I. Efficacy of a quadrivalent rhesus rotavirusbased human rotavirus vaccine aimed at preventing severe rotavirus diarrhea in infants and young children. J. Infect. Dis. 174, S65-S72 (1996).

2. Perez-Schael, I. et al. Efficacy of the rhesus rotavirusbased quadrivalent vaccine in infants and young children in Venezuela. N. Engl. \%. Med. 337, 1181-1187 (1997).

3. Joensuu, I., Koskenniemi, E., Pang, X.-L. \& Vesikari, T. Randomised placebo-controlled trial of rhesushuman reassortant rotavirus vaccine for prevention of severe rotavirus gastroenteritis. Lancet 350 1205-1209 (1997).

4. Bishop, R.F., Davidson, G.P., Holmes, I.H. \& Ruck, B.J. Virus particles in epithelial cells of duodenal mucosa from children with viral gastroenteritis. Lancet i, 1281-1283 (1973)

5. Institute of Medicine The prospects of immunizing against rotavirus p.D13-1 to D13-12. In New Vaccine Development: Diseases of Importance in Developing Countries Vol. 2 (National Academy Press, Washington DC, 1986).

6. Bishop, R.F., Barnes, G.L., Sipriani, E. \& Lund, I.S. Clinical immunity after neonatal rotavirus infection a prospective longitudinal study in young children. N. Eng. I. Med. 309, 72-76 (1983).

7. Velazquez, F.R. et al. Rotavirus infection in infants and protection against subsequent infections. $N$. Eng. 1. Med. 335, 1022-1028 (1996).

8. Glass, R.I. et al. The epidemiology of rotavirus diarrhea in the United States: surveillance and estimates of disease burden. J. Infect. Dis. 174, S5-S11 (1996).

9. Smith, I., Haddix, A., Teutsch, S. \& Glass, R.I. Cost effectiveness analysis of a rotavirus immunization program for the United States. Pediatrics 96, 609-615 (1995).

10. Rennels, M.B. et al. Safety and efficacy of high-dose rhesus-human reassortant rotavirus vaccines-report of the national multicenter trial. Pediatrics 97, 7-13 (1996).

11. Santosham, M. et al. Efficacy and safety of highdose rhesus-human reassortant rotavirus vaccine in native American populations /. Ped. 131, 632-638 (1997).

${ }^{1}$ Viral Gastroenteritis Section

National Center for Infectious Diseases

Centers for Disease Control and Prevention

1600 Clifton Road

Atlanta, Georgia 30333, USA

${ }^{2}$ CVI c/o World Heatth Organization

20 Avenue Appia

1211 Geneva 27, Switzerland 